\title{
Regional variation in acute care length of stay after orthopaedic surgery total joint replacement surgery and hip fracture surgery
}

\author{
John D. FitzGerald ${ }^{1}$, Haoling H. Weng ${ }^{2}$, Nelson F. Soohoo ${ }^{3}$, Susan L. Ettner ${ }^{1}$ \\ 1. Department of Medicine, University of California, Los Angeles, CA, USA. 2. Merck Inc., Kenilworth, NJ, USA. 3. \\ Department of Orthopedic Surgery, University of California, Los Angeles, CA, USA
}

Correspondence: John D. FitzGerald. Address: Department of Medicine, University of California at Los Angeles, Rehabilitation Center, Room 32-59, Los Angeles, CA 90095-1670, USA. E-mail: jfitzgerald@mednet.ucla.edu

Received: March 18, 2013

Accepted: April 14, 2013

Online Published: June 6, 2013

DOI : $10.5430 /$ jha.v2n4p71

URL: http://dx.doi.org/10.5430/jha.v2n4p71

\section{Abstract}

Objective: To examine change in regional variations in acute care length of stay (LOS) after orthopedic surgery following expiration of the New York (NY) State exemption to the Prospective Payment System and implementation of the Medicare Short Stay Transfer Policy.

Methods: Time series analyses were conducted to evaluate change in LOS across regions after policy implementations. Small area analyses were conducted to examine residual variation in LOS. The dataset included A 100\% sample of fee-for-service Medicare patients undergoing surgical repair for hip fracture or elective joint replacement surgery between 1996 and 2001.

Data files from Centers for Medicare and Medicaid Services 1996-2001 Medicare Provider Analysis and Review file, 1999 Provider of Service file, and data from the 2000 United States Census were used for analysis.

Results: In 1996, LOS in NY after orthopedic procedures was much longer than the remainder of the country. After policy changes, LOS fell. However, significant residual variation in LOS persisted. This residual variation was likely partly explained by differences variation in regional managed care market penetration, patient management practices and unmeasured characteristics associated with the hospital location.

Conclusions: NY hospitals responded to changes in reimbursement policy, reducing variation in LOS. However, even after 5 years of financial pressure to constrain costs, other factors still have a strong impact on delivery of patient care.

\section{Key words}

Small Area Analysis, Surgery, Geographic/Spatial factors/Small area variations, Medicare

\section{I ntroduction}

Small area variation studies are conducted to use the observed variation in outcomes (e.g. utilization rates or mortality) across regions to explore the care factors associated with that regional variation. Prior small area variation studies have demonstrated that length of stay (LOS) for acute care hospitalizations is longer on the east coast than the west 
coast $^{[1,2]}$. With implementation of Medicare’s Prospective Payment System (PPS) in October $1983^{[3]}$, hospitals had the financial incentive to discharge patients earlier and responded with reductions in LOS ${ }^{[4]}$. These preset payments were determined by regional historical costs, which were highly correlated with regional historical LOS. Therefore regions with higher historical costs and longer LOS continued to receive higher payments and perhaps had less pressure to change their practices.

New York (NY) hospitals were initially exempt from the impact of PPS operating under the NY Prospective Hospital Reimbursement Methodology. Under this program, NY inpatient hospital rates were set by the NY State Health Department (for all payors), which provided annual increases as well reimbursements for indigent care and graduate medical education until the exemption expired January $1997^{[5]}$.

NY would have also been differentially affected by implementation of the Medicare Short Stay Transfer Policy (SSTP), implemented in October 1998. This policy discounted payments for patients discharged "early" (defined by discharge prior to the national geometric mean LOS for the relevant Diagnostic Related Group) to post-acute care facilities thereby removing some of the incentive to discharge patients early. After implementation of this policy, the historical steady decline in acute care LOS seen across the country ended ${ }^{[6]}$. With longer than average LOS in NY, patients discharged from NY State hospitals would have been partly protected from the fiscal impact of this policy. The differential impact of this policy change ought to have further reduced differences in LOS between NY and other regions.

With expiration of the NY State exemption and implementation of the Medicare Short Stay Transfer Policy, we postulated that hospital LOS for NY State would fall to comparable lengths of stay with other regions around the country.

The Dartmouth Atlas can be used to examine such trends ${ }^{[7]}$. Using their data, we calculated the adjusted mean LOS for NY State and the US average using the total (age, sex and race adjusted) number of hospital days and discharges for all fee for service surgical discharges for all fee for service for Medicare enrollees aged 65-99.

These data show that in 1996, the adjusted mean LOS for the Nation was 7.6 days while in NY State it was 11.5 days (difference of 3.9 days). By 2001, the adjusted mean National LOS fell to 6.8 days while NY fell to 9.3 days (difference of 2.6 days). These trends continued through 2005 where the National LOS fell further to 6.3 days and NY fell to 8.2 days (difference 1.9 days). This current NY 2 day difference remains 30\% greater than the US average.

To study the impact of the aforementioned policy changes on NY state LOS, using data we had previously obtained from CMS we performed a more detailed regional analyses for select surgical conditions. We selected patients undergoing surgical repair of hip fracture (FX) or joint replacement surgery (JR) between 1996 and 2001 because the majority of these patients are covered by Medicare and stood out as some of the Diagnosis Related Groups with the greatest regional variation in $\operatorname{LOS}^{[8]}$. Though these data are older than the Dartmouth data, we conducted more detailed analyses to examine whether there might be important patient, hospital or regional covariates associated with length of stay not analyzed in the Dartmouth data. We further conducted small area analyses to determine whether patient or hospital factors were associated with residual unexplained variation. Identifying the etiology of variation in practice patterns could identify potential inefficiencies that could be targeted for cost savings.

\section{Patients and methods}

\subsection{Patient selection}

We selected a 100\% national sample of fee-for-service Medicare patients who underwent FX or JR surgery between 1996 and 2001 (Cost constraints prohibited us from purchasing supplemental years). Inpatient claims from the Medicare provider analysis and review (MEDPAR) and denominator files were selected for all fee-for-service Medicare patients. 
Patients undergoing surgical repair of hip fracture were identified with an ICD-9 diagnosis of 820.xx in any one of the 10 diagnostic code positions. Surgical repair of hip fracture was confirmed with the hip replacement codes $81.51-81.53$ or pinning codes 79.35 , 79.15 or 78.55. Patients treated non-surgically for hip fracture were excluded. The final national sample included totals 1,158,299 discharges.

Patients undergoing JR surgery were identified by Diagnosis Related Group codes 209 and 471 . Verification of surgery and inclusion in the study sample was confirmed by ICD-9 procedure codes $81.51-81.55$. Patients undergoing joint replacement for clearly non-elective reasons were excluded from analysis (e.g. fracture, infection or major trauma). Sensitivity analyses conducted for the full sample of JR patients and the smaller sample of elective JR revealed no meaningful differences and results for the smaller more clinically homogenous sample of patients are presented. The final national sample included 1,232,427 discharges.

\subsection{Primary outcome (length of stay)}

Length of stay was abstracted from the Medicare provider analysis and review (MEDPAR) files. For the $0.5 \%$ of fracture patients and the $0.3 \%$ of elective JR patients who were transferred between acute care hospitals, the total LOS was summed for all hospitals.

\subsection{I ndependent variables}

\subsubsection{Regional variation between 1996 and 2001}

Regional variation in LOS was examined at the national level, comparing LOS across Centers for Medicare and Medicaid Services (CMS) regions. CMS divides the country into 10 large regions, naming each region by the city where the regional fiduciary office resides (See map of continental CMS regions in Appendix.). The NY region includes NY and New Jersey (NJ) States, Puerto Rico and the US Virgin Islands (both territories excluded from analyses). NY State represents 65\% of all FX discharges and 69\% of all JR discharges in the CMS NY region.

Adjusted multivariate analyses (see list of covariates below) were conducted to describe monthly regional LOS across the 10 CMS regions using 72 dummy variables to represent the calendar months between January 1996 and December 2001 and 10 dummy variables to represent the CMS regions. Separate dummy variables were generated to describe calendar year averages. Regions are convenient for graphic summaries of National data. Similar analyses conducted for individual states revealed similar results. The regional results are described for ease of clarification.

To more closely examine regional variation around NY State, unadjusted county median LOS for discharges between 1996 and 2001 were calculated and presented using ArcView geographic information system software ${ }^{[9]}$. Smaller numbers of patients per county precluded multivariate analyses. Attributable to smaller numbers of patients per county, median values were reported to account for outlier LOS.

\subsubsection{Small area regional variation in 2001}

To examine residual regional variation after the NY State exemption and the SSTP, for 2001 hospitalizations, we selected NY State, the surrounding states New Jersey (NJ), Pennsylvania (PA), New England (NE: Vermont, New Hampshire, Massachusetts, Rhode Island, Connecticut) and California (CA) as a large populous comparator western state to conduct further multivariate analyses. Sequential multivariate models tested whether addition of groups of covariates (demographic, socio-economic estimates, comorbidities, surgical, hospital, or regional) significantly affected variation in LOS.

To further test whether potential unmeasured characteristics associated with either hospital location or patient residence influenced LOS, multivariate analyses were conducted selecting patients residing in counties bordering the NY Stateline. 


\section{Covariates}

To control for potential confounders, patient characteristics were abstracted from the Medicare denominator files. Patient-level covariates included demographic (age, gender and ethnicity), socioeconomic (income as estimated by median income from the patients home zip code and whether patient was eligible for state aid health insurance), and clinical characteristics, including type of surgery (pinning vs. hip replacement for FX patients and knee vs. hip replacement for JR patients) and the Charlson comorbidity index ${ }^{[10]}$.

Hospital characteristics, including bed size, type of ownership (not-for-profit, for-profit, government) and teaching status, were abstracted from the 2001 Provider of Service file.

Figure 1a. Adjusted mean hospital length of stay by region for surgical repair of hip fracture between 1996 and 2001.

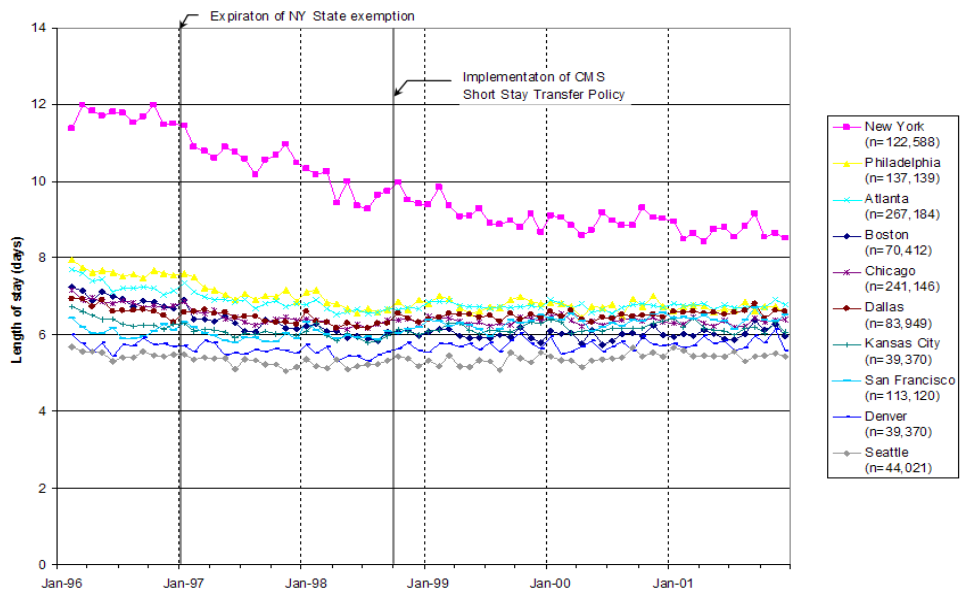

Regional characteristics included population count of persons aged greater than 65 from the 2000 US census, the proportion of the patient's resident county that was rural, and supply variables, including the sum total of acute care beds, skilled nursing facility beds, rehabilitation beds, home health nurses, therapists and aides in the patient's resident zip code from the 2001 Provider of Service file and 2001 county level HMO Medicare market penetration ${ }^{\text {[11] }}$.

Figure 1b. Adjusted mean hospital length of stay by region for elective joint replacement surgery from 1996 to 2001.

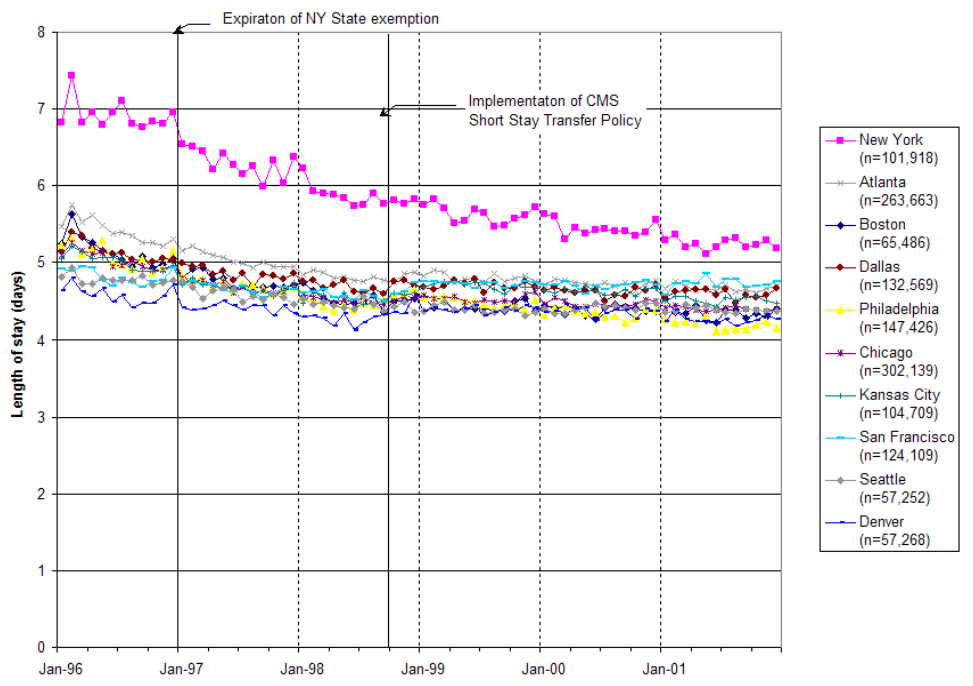




\section{Statistical methods}

All analyses were performed separately for JR and hip FX patients. For all multivariate regression analysis, random effects mixed linear models were conducted to evaluate mean LOS, controlling for all of the aforementioned covariates and within-hospital clustering. To describe differences between calendar years, spline models ${ }^{[12]}$ were used to smooth variation within each of the respective annual time periods.

All analyses were conducted using either SAS $8.2^{[13]}$ or Intercooled STATA $7^{[14]}$. Owing to the large sample size and multiple comparisons, only tests of $p<0.0001$ were reported as significant.

Table 1. Demographic and Comorbidities Characteristics of FX patients

\begin{tabular}{|c|c|c|c|c|c|}
\hline & $\begin{array}{l}\text { NY } \\
n=11,102\end{array}$ & $\begin{array}{l}\text { CA } \\
n=11,611\end{array}$ & $\begin{array}{l}\text { NJ } \\
n=5,930\end{array}$ & $\begin{array}{l}\text { PA } \\
n=9,965\end{array}$ & $\begin{array}{l}\mathrm{NE} \\
\mathrm{n}=\mathbf{1 0 , 4 2 8}\end{array}$ \\
\hline Age (Mean years) & 82.8 & $82.2^{*}$ & 82.6 & 82.7 & 83.0 \\
\hline Female (\%) & 78.0 & $74.8^{\dagger}$ & 77.8 & 78.6 & 78.5 \\
\hline Caucasian (\%) & 93.7 & $88.1^{\dagger+}$ & 94.2 & $96.2^{\S}$ & $97.1^{\S}$ \\
\hline \multicolumn{6}{|l|}{ Comorbidities } \\
\hline DM (\%) & 15.7 & $14.3^{* *}$ & 17.0 & $17.3^{++}$ & 14.9 \\
\hline CHF (\%) & 14.8 & 13.7 & 14.0 & 15.5 & 15.0 \\
\hline COPD (\%) & 16.9 & $20.3^{\text {\# }}$ & 17.9 & 19.1 & 19.4 \\
\hline Dementia (\%) & $17.3^{\S \S}$ & 19.2 & 20.0 & 21.5 & 21.3 \\
\hline Charlson (mean) & $1.18^{* * *}$ & 1.21 & 1.24 & 1.30 & 1.27 \\
\hline Pinning (\%) & 65.4 & $61.4^{\dagger+\dagger}$ & 63.3 & 64.1 & 65.1 \\
\hline Medicaid coinsurance (\%) & $11.1^{\text {杖 }}$ & $27.8^{\S \S \S}$ & 15.4 & 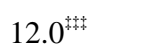 & 16.3 \\
\hline Estimated median income $(\$ 000)^{* * * *}$ & 48.9 & 50.1 & 58.5 & 42.1 & 53.3 \\
\hline
\end{tabular}

*Younger patients in CA than NY and NE $(p<0.0001)$.

† Lower proportion of women suffering hip fracture in CA than all other states.

‡ Lower proportion of Caucasian patient suffering hip fracture in CA than all other states.

$\S$ Greater proportion of Caucasian patients in NE and PA vs. NJ and NY.

** Diabetes coded lower in CA than NJ and PA.

†十 Diabetes coded higher in PA than NE and CA.

杭 COPD coded higher in CA than NY.

$\S \S$ Dementia coded lower in NY than NJ, NE and PA.

*** Charlson score lower in NY than PA.

$+\dagger+$ Lower proportion of pinning in CA than NE and NY.

\#\# Lower proportion of patients eligible for state medical aid in NY and PA than other states.

$\S \S \S$ Higher proportion of patients eligible for state medical aid in CA than other states.

***** All estimated income values uniquely different for each state $(p<0.0001)$.

\section{Results}

\subsection{Change in length of stay by CMS region: 1996-2001 (Figure 1)}

In 1996, there was significant variation in LOS by CMS region. Among FX patients, the NY region had an adjusted mean LOS almost double that of the remainder of the country (11.7 vs. 6.8, $p<0.0001$, Figure 1a).

Prior to the expiration of the NY exemption, the adjusted mean LOS in the NY region during 1996 was 11.7 days. After expiration of the exemption, the adjusted mean LOS in NY fell from 1997 to 1998 and 1999 from 10.8 to 9.8 and 9.2 days 
(each per annum change significantly different than prior year, $p<0.0001$ ) before flattening out in 2000 and 2001 (9.0 and 8.7 respectively, not significantly different than each prior year).

However, even well after the expiration of the NY State exemption and the SSTP, by 2001, NY remained a significant outlier with a mean LOS of 8.7 vs. 6.4 for the other regions $(p<0.0001)$.

Table 2. Demographic and Comorbidities Characteristics of JR patients

\begin{tabular}{|c|c|c|c|c|c|}
\hline & $\begin{array}{l}\text { NY } \\
n=14,759\end{array}$ & $\begin{array}{l}\text { CA } \\
n=17,572\end{array}$ & $\begin{array}{l}\text { NJ } \\
n=5,535\end{array}$ & $\begin{array}{l}\text { PA } \\
n=15,091\end{array}$ & $\begin{array}{l}\text { NE } \\
n=12,033\end{array}$ \\
\hline Age (mean years) & 73.9 & 73.9 & 74.2 & 74.3 & 74.2 \\
\hline Female (\%) & 65.9 & 64.7 & 66.1 & 66.5 & 65.1 \\
\hline Caucasian $(\%)^{*}$ & 90.4 & 86.4 & 88.9 & 94.6 & 95 \\
\hline \multicolumn{6}{|l|}{ Comorbidities } \\
\hline $\mathrm{DM}(\%)$ & 13.0 & $11.5^{\dagger}$ & 14.3 & $16.4^{\ddagger}$ & 13.6 \\
\hline CHF (\%) & 3.6 & 3.1 & 3.4 & $4.1 \S$ & 4.0 \\
\hline COPD (\%) & 11.3 & 11.1 & 10.5 & 12 & 12 \\
\hline Dementia (\%) & 0.9 & 1.1 & 1 & 1 & 1.4 \\
\hline Charlson (mean) ${ }^{* *}$ & 0.70 & 0.68 & 0.71 & 0.77 & 0.76 \\
\hline $\begin{array}{l}\text { Proportion of Hip replacements (as } \\
\text { opposed to Knee replacement) }\end{array}$ & 44.3 & 43.1 & $40.3^{\dagger+}$ & $35.9^{\dagger+}$ & 43.1 \\
\hline Medicaid coinsurance (\%) & $7.2^{\ddagger \ddagger}$ & $20.6^{\S \S}$ & 9.2 & $7.2^{\text {护 }}$ & 9.9 \\
\hline $\begin{array}{l}\text { Mean estimated income ( } \$ 000) \text { based } \\
\text { on patient's residence census tract }\end{array}$ & 50.4 & 51.3 & 59.1 & 42.1 & 53.8 \\
\hline
\end{tabular}

\footnotetext{
* Proportion of Caucasian patients all uniquely different for all states $(p<0.0001)$ except between NE and PA.

† Diabetes coded lower in CA than NE, NJ and PA $(p<0.0001)$.

$\ddagger$ Diabetes coded higher in PA than all other states $(p<0.0001)$.

$\S$ CHF coded higher in PA than CA $(p<0.0001)$.

** Charlson scores higher in PA and NE than CA and NY $(p<0.0001)$.

$+\dagger$ Lower proportion of hip replacements in PA and NJ than other states $(p<0.0001)$.

枺 Lower proportion of patients eligible for state medical aid in NY and PA than all other states $(p<0.0001)$.

$\S \S$ Higher proportion of patients eligible for state medical aid in CA than all other states $(p<0.0001)$.

***All estimated income values uniquely different $(p<0.0001)$ except between NY and CA.
}

Similar though weaker trends were noted among JR patients. Prior to the expiration of the exemption, in 1996 LOS was higher in NY than other regions (7.2 vs. $5.2 p<0.0001$, Figure 1b). LOS fell for all regions through 1998 and continued to fall in NY through 2001 so that by that year, NY remained a statistical outlier (5.1 vs. 4.4, $p<0.0001$ ) though the magnitude of the variation was less than that of FX patients.

\subsection{Detailed 2001 regional analysis for select states}

To examine the residual regional variation we performed the following small area analyses. To examine variation by state, we selected patients hospitalized in 2001 in NY, the neighboring states and CA as a comparator populous state.

Patient (Table 1 and Table 2), hospital, regional, and post-acute care characteristics (Table 3) are provided in the Appendix. The mean age for NY patient undergoing surgical repair of FX was 82.8 years (CA patients 0.6 months younger), 78\% female (CA - 75\%), 94\% Caucasian (CA - 88\%). NY FX patients had slightly less comorbidity than NY or PA. $65 \%$ of NY patients underwent pinning (only 61\% in CA). CA patients had much higher proportion of patients on state Medicaid than other states. 
Among JR patients, the mean NY patient was 74 years of age, 66\% female, 90\% Caucasian (no significant differences across the other states). The mean number of comorbidities was 0.7 . The proportion of hip to knee replacement was slightly lower in NJ and PA compared to other states. CA again had higher proportion of state Medicaid (See appendix for detail).

Table 3. Hospital, regional characteristics, post-acute care supply characteristics

\begin{tabular}{|c|c|c|c|c|c|}
\hline & NY & CA & $\mathbf{N J}$ & PA & NE \\
\hline $\begin{array}{l}\text { Number of Fractures } \\
\text { Number of Joint Replacements }\end{array}$ & $\begin{array}{l}n=11,102 \\
n=14,759\end{array}$ & $\begin{array}{l}n=11,611 \\
n=17,572\end{array}$ & $\begin{array}{l}n=5,930 \\
n=5,535\end{array}$ & $\begin{array}{l}n=9,965 \\
n=15,091\end{array}$ & $\begin{array}{l}n=10,428 \\
n=12,033\end{array}$ \\
\hline Population aged $\geq 65(000)^{*}$ & 2,448 & 3,596 & 1,113 & 1,919 & 1,892 \\
\hline Incident FX Rate (per 000) & 4.5 & 3.2 & 5.3 & 5.2 & 5.5 \\
\hline Incident JR Rate (per 000) & 6.0 & 4.9 & 5.0 & 7.9 & 6.4 \\
\hline \multicolumn{6}{|l|}{ Acute Care Bed Supply ${ }^{\dagger}$} \\
\hline Hospitals (n) & 188 & 338 & 80 & 174 & 142 \\
\hline Acute Care Beds (000) & 64.5 & 80.7 & 28.9 & 44.5 & 28.9 \\
\hline Beds per 000 capita & 2.9 & 4.2 & 2.8 & 3.9 & 4.9 \\
\hline \multicolumn{6}{|l|}{ Hospital ownership (\% beds) } \\
\hline For profit & 80.7 & 62.6 & 94.1 & 95.5 & 96.6 \\
\hline Non profit & 2.4 & 14.5 & 0.0 & 4.5 & 0.7 \\
\hline Government & 16.9 & 22.8 & 5.9 & 0.0 & 2.7 \\
\hline Teaching hospital $^{\dagger}$ (\% beds) & 25.9 & 64.4 & 41.7 & 44.9 & 38.1 \\
\hline \multicolumn{6}{|l|}{ Post-Acute Care Supply $^{\dagger}$} \\
\hline Skilled Nursing Facilities (n) & 700 & 1576 & 411 & 897 & 1124 \\
\hline SNF beds (per 000 capita) & 2,706 & 2,317 & 1,003 & 1,612 & 2,805 \\
\hline Inpatient Rehabilitation Facilities (n) & 5 & 13 & 10 & 25 & 13 \\
\hline RH beds (per 000,000 capita) & 201 & 198 & 863 & 1156 & 607 \\
\hline Home Health Agencies (n) & 257 & 1424 & 75 & 608 & 611 \\
\hline RN + LPN (per 000 capita) & 3.43 & 8.79 & 1.87 & 4.37 & 8.29 \\
\hline HH aides (per 000 capita) & 1.08 & 2.50 & 1.65 & 1.85 & 9.91 \\
\hline PT + OT(per 000 capita) & 0.63 & 0.81 & 0.42 & 0.46 & 1.05 \\
\hline Total HH staffing & 5.14 & 12.1 & 3.94 & 6.68 & 19.25 \\
\hline $\begin{array}{l}\text { Other Regional Characteristics } \\
\text { HMO market share }(\%)^{\ddagger}\end{array}$ & 16.8 & 36.9 & 15.8 & 26.3 & 18.4 \\
\hline Population rural (\%) & 12.5 & 5.5 & 5.7 & 23.0 & 19.4 \\
\hline
\end{tabular}

* US 2000 Census;

† Provider of Service file 2001;

‡ Centers for Medicare \& Medicaid Services (2001). Managed Care Quarterly State/County Data Files

\subsection{State-level variation in Multivariate Adjusted Length of stay, 2001 (Table 3)}

After controlling for patient, hospital and regional covariates, 2001 mean LOS in NY, CA, NJ, PA and NE were 8.8, 6.5, 7.7, 6.5 and 6.2 days respectively (Table 4). LOS was significantly longer in NY and NJ than all other states $(p<0.0001)$. 
Similar variation was noted for JR patients, with adjusted mean LOS in NY, CA, NJ, PA and NE equal to 5.2, 4.7, 4.4, 4.1 and 4.3 days respectively. Again, NY LOS was significantly longer than all other states $(p<0.0001)$.

Table 4. Adjusted hospital mean length of stay across 5 states for 2001

\begin{tabular}{|c|c|c|c|c|c|}
\hline & $\overline{N Y}$ & CA & NJ & $\overline{\mathbf{P A}}$ & New England \\
\hline Hip Fracture Surgery ${ }^{*}$ & $\mathrm{n}=12,043$ & $n=11,652$ & $n=6,244$ & $\mathrm{n}=10,307$ & $\mathrm{n}=9,571$ \\
\hline Length of Stay (days) & 8.8 & 6.5 & 7.7 & 6.5 & 6.2 \\
\hline Elective Joint Replacement ${ }^{\dagger}$ & $\mathrm{n}=11,102$ & $\mathrm{n}=11,611$ & $\mathrm{n}=5,930$ & $\mathrm{n}=9,965$ & $\mathrm{n}=10,428$ \\
\hline Length of Stay (days) & 5.2 & 4.7 & 4.4 & 4.1 & 4.3 \\
\hline
\end{tabular}

NNY and NJ LOS significantly longer than all other states LOS $(p<0.0001)$. No significant differences between CA, PA and NE LOS.

${ }^{\dagger} \mathrm{NY}$ LOS significantly longer than all other states $(p<0.0001)$. CA LOS significantly longer than PA $(p<0.0001)$.

Through sequential linear regressions, we tested whether groups of covariate were associated with variation in LOS. Among FX patients, the addition of patient, institutional or regional characteristics did little to explain variation in LOS. However, county-level Medicare managed care penetration explained the majority of the reduction in variation (reducing the LOS difference between NY and PA from 2.6 to 2.3 days).

Figure 2a. Unadjusted median hospital length of stay for surgical repair of hip fracture by county 1996 - 2001*.

*Blank areas represent counties where no surgeries were performed.

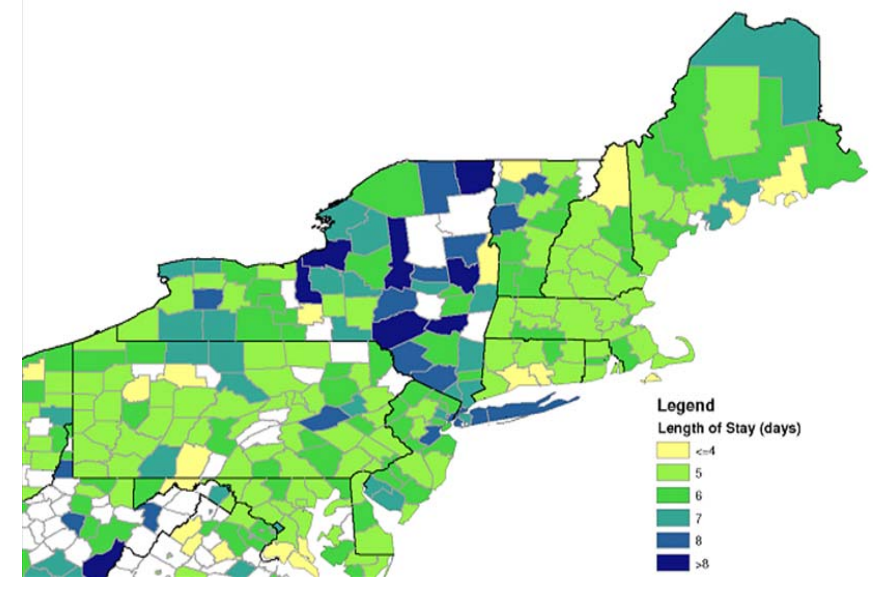

Figure 2b. Unadjusted median hospital length of stay for elective joint replacement by county $1996-2001 *$.

*Blank areas represent counties where no surgeries were performed.

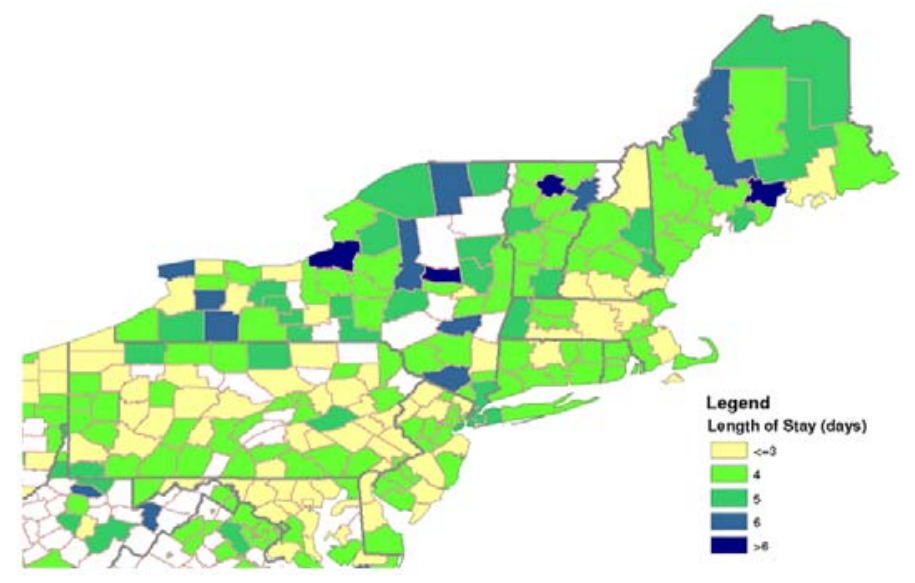


Similarly among JR patients, adding patient, institutional or regional characteristics did little to adjust regional LOS variation. The addition of managed care penetration and day of week of admission (another marker of patient care management) reduced variation in LOS between NY and PA from 1.5 to 1.1 days.

\subsection{Variation in Length of Stay by county: 1996-2001 (Figure 2)}

Turning attention to small area analyses, the unadjusted median LOS by county for FX and JR patients were mapped to illustrate that patients undergoing surgery in NY counties had longer median LOS than other regional counties (Figures 2a \& b). The majority (64\%) of counties in NY State had a median LOS of 7 days or longer after FX while the surrounding states had few counties (9\%) with median LOS of 7 days or longer. Similar findings are noted for JR patients with NY State having a greater proportion (53\%) of counties with median LOS of 5 days or longer, other states (8\%).

\subsection{Cross NY Stateline multivariate analyses, 2001 (Table 5)}

Table 5. Cross Border Analysis Among Comparing Adjusted Mean Length of Stay for Patients Residing in Counties Bordering the New York State Line in 2001

\begin{tabular}{|c|c|c|c|c|c|}
\hline Number of FX patients & $\begin{array}{l}\text { NY hospital and } \\
\text { NY patient }\end{array}$ & $\begin{array}{l}\text { NY hospital and } \\
\text { Out of state } \\
\text { patient }\end{array}$ & $\begin{array}{l}\text { Out of state } \\
\text { Hospital and } \\
\text { NY patient }\end{array}$ & $\begin{array}{l}\text { Out of state } \\
\text { Hospital and } \\
\text { Patient }\end{array}$ & $\begin{array}{l}\text { Mean } \\
\text { hospital or } \\
\text { patient } \\
\text { effect }\end{array}$ \\
\hline Hip Fracture Surgery & $\mathrm{n}=6,090$ & $n=226$ & $\mathrm{n}=121$ & $\mathrm{n}=2,715$ & \\
\hline Effect of Hospital location $\rightarrow$ & & $\mathrm{DIF}=1.5$ & $\mathrm{DIF}=1.5$ & & $1.5^{*}$ \\
\hline Length of stay (days) & 9.1 & & & 7.0 & \\
\hline Effect of Patient residence $\rightarrow$ & \multicolumn{2}{|l|}{$\mathrm{DIF}=0.6$} & \multicolumn{2}{|c|}{$\mathrm{DIF}=0.6$} & 0.6 \\
\hline Elective Joint Replacement & $\mathrm{n}=4,407$ & $\mathrm{n}=304$ & $\mathrm{n}=72$ & $\mathrm{n}=2,541$ & \\
\hline Effect of Hospital location $\rightarrow$ & & $\mathrm{DIF}=0.4$ & $\mathrm{DIF}=0.3$ & & 0.4 \\
\hline Length of stay (days) & 5.2 & 5.1 & 4.8 & 4.8 & \\
\hline Effect of Patient residence $\rightarrow$ & $\mathrm{DIF}=0.1$ & & $\mathrm{DIF}=$ & & 0.1 \\
\hline
\end{tabular}

${ }^{*} p<0.0001$

To examine for potential unmeasured factors associated with either patient residence or hospital factors, patients in counties bordering the NY Stateline were selected for further analysis. All patients (whether from NY or out of state) had longer LOS if they were admitted to NY hospitals rather than out-of-state hospitals (mean difference $=1.5, p<0.0001$, Table 5). In contrast, there was little difference in LOS when patient residence varied while hospital location was held constant (mean difference $=0.6, p=\mathrm{NS}$ ). These results suggest that unmeasured hospital characteristics (e.g. physician practice patterns) rather than patient residence (e.g. unmeasured local post-acute care or patient factors) account for variation in LOS. Similar results, though smaller magnitude, were noted for JR patients. 


\section{Discussion}

The above analyses provide some insight into physician and hospital behaviors in response to reimbursement policy changes. Focusing on common surgical procedures and using the $100 \%$ sample of patients permitted us to model month-to-month changes in LOS, which better correlates changes in utilization with changes in policy implementation. Using the $100 \%$ sample, we were also able to conduct small area cross-state border analyses to show that hospital factors better explained variation than patient residence factors.

With expiration of the PPS exemption and implementation of the SSTP, there was partial attenuation of the regional variation in LOS. However, there was significant residual regional variation with NY remaining a significant outlier.

Analyses of residual variation in LOS in 2001 demonstrated that patient care management factors (managed care penetration and day of discharge management) rather than measured patient, hospital or other regional covariates explained some of this residual variation. Other authors have also noted that Medicare patients switching from Fee for Service plans to managed care plans resulted in subsequent shorter length of stay ${ }^{[15]}$. Furthermore, as we observed, it has been previously reported that increased regional managed care penetration is associated with decreased length of stay even among the non-managed care Medicare patients ${ }^{[16]}$.

Our cross-border analyses suggest that residual variation in LOS is better explained by (unmeasured) hospital characteristics rather than (unmeasured) characteristics associated with patient residence. Other authors have stressed the importance of social norms, reporting that physicians operating in more than 1 hospital tend to adopt patterns of care specific for each separate hospital ${ }^{[17,18]}$. Other possible unmeasured hospital factors known to be associated with reductions in LOS include implementation of practice guideline pathways ${ }^{[19]}$.

These interpretations are limited as our most recent data is from 2001. However, the data covers the periods where policy changes would have affected physician and hospital administration behaviors. Furthermore, Dartmouth data shows continued, persistent differences in LOS through 1995 without sudden change in historical trends suggesting that the factors affecting care in 2001 were persistent at least through 2005. Our analyses our further limited by the nature of administrative data, there were only a few observed factors (managed care market share penetration and day of discharge) associated with variation in LOS. However, by using $100 \%$ sample for well-defined conditions, we were able to limit the clinical heterogeneity across diverse medical conditions. We were also able to conduct small area analyses that suggested (unmeasured) hospital factors explain some of the variation. Further studies collecting primary data would be required to explore this suggested association.

Variation in hospital utilization has existed for decades. A better understanding into the reasons for some of this variation could identify areas of inefficiency and lead to significant reductions in cost of care. Despite large changes in reimbursement policy implemented during these study years, only a portion of variation in LOS was eliminated even 4 years after the expiration of the NY State exemption. Measured factors did little to explain the regional variation (with the exception of a small effect from managed care penetrance and day of discharge) suggesting that other unmeasured factors explain the variation. Hospital associated factors that might affect residual variation include hospital based physician practice patterns that may have significant impact on differential patient care.

\section{Conclusion}

NY hospitals responded to changes in reimbursement policy, reducing variation in LOS with each change in policy. However, significant residual differences between NY and other regions persist. Factors associated with managed care explained some of the variation in LOS. Our small area, cross-border analyses suggest that (unmeasured) hospital factors rather than (unmeasured) patient factors likely explain an additional component of the residual variation in LOS. 


\section{References}

[1] Knickman, J. R. \& Foltz, A. M. Regional differences in hospital utilization. How much can be traced to population differences? Med.Care. 1984; 22: 971-986. http://dx.doi.org/10.1097/00005650-198411000-00001

[2] Taylor, C. L., Yuan, Z., Selman, W. R., Ratcheson, R. A., \& Rimm, A. A. Mortality rates, hospital length of stay, and the cost of treating subarachnoid hemorrhage in older patients: institutional and geographical differences. J Neurosurg. 1997; 86: 583-588. PMid:9120619 http://dx.doi.org/10.3171/jns.1997.86.4.0583

[3] Federal Register, Medicare program; limitations on reimbursable hospital costs and the rate of hospital cost increases--HCFA. Final rules. Fed.Regist. 1983; 48: 39412-39423. PMid:10273388

[4] Fitzgerald, J. F., Moore, P. S., \& Dittus, R. S. The care of elderly patients with hip fracture. Changes since implementation of the prospective payment system. N.Engl.J.Med. 1988; 319: 1392-1397. PMid:3185650 http://dx.doi.org/10.1056/NEJM198811243192106

[5] Whalen, D. (1996). New York State Medicare Prospective Payment System exemption. New York State Department of Health: Office of Health Systems Management [Internet]. November 4, 1996. World Wide Web [Announcement posted on the World Wide Web]. Available from: www.health.state.ny.us/nysdoh/hcra/main.htm.

[6] FitzGerald JD, Boscardin WJ, Hahn BH, Ettner SL. Impact of the Medicare Short Stay Transfer Policy on patients undergoing major orthopedic surgery. Health Serv Res. 2007 Feb; 42(1 Pt 1): 25-44. PMid:17355580 http://dx.doi.org/10.1111/j.1475-6773.2006.00606.x

[7] The Dartmouth Atlas of Health Care "Understanding of the Efficiency and Effectiveness of the Health Care System” [Internet]. Available from: www.dartmoujthatlas.org.

[8] Latta VB, Keene RE. Leading inpatient surgical procedures for aged Medicare beneficiaries.” Health Care Financ Rev. 1989 Winter; 11(2): 99-110. PMid:10318368

[9] ArcGIS (2007). (Version 9.2) [Computer software]. Redlands, CA: ESRI.

[10] Charlson, M. E., Pompei, P., Ales, K. L., \& MacKenzie, C. R. A new method of classifying prognostic comorbidity in longitudinal studies: development and validation. Journal of Chronic Diseases. 1987; 40: 373-383. http://dx.doi.org/10.1016/0021-9681(87)90171-8

[11] Centers for Medicare \& Medicaid Services (2001). Managed Care Quarterly State/County Data Files [Internet]. Available from: www.cms.gov/healthplans/statistics/mpsct/

[12] Marsch CL, Cormier DR. Spline Regression Models. Thousand Oaks, CA: Sage Publications, Inc, 2001.

[13] SAS Institute (2000). SAS Software Version 8.2 (Version 8.2) [Computer software]. Cary, North Carolina: The SAS Institute.

[14] STATA (2002). Stata (Version Intercooled 7.0 for Windows 98/95/NT) [Computer software]. College Station, TX: Stata Corporation.

[15] Dhanani, N., O'Leary, J. F., Keeler, E., Bamezai, A., \& Melnick, G. The effect of HMOs on the inpatient utilization of medicare beneficiaries. Health Serv Res. 2004; 39: 1607-1627. PMid:15333125 http://dx.doi.org/10.1111/j.1475-6773.2004.00306.x

[16] Baker, L. C. Association of managed care market share and health expenditures for fee-for-service Medicare patients. JAMA JID 7501160. 1999; 281: 432-437. http://dx.doi.org/10.1001/jama.281.5.432

[17] de Jong, J. D., Westert, G. P., Lagoe, R., \& Groenewegen, P. P. Variation in hospital length of stay: do physicians adapt their length of stay decisions to what is usual in the hospital where they work? Health Serv Res. 2006; 41: 374-394. PMid:16584454 http://dx.doi.org/10.1111/j.1475-6773.2005.00486.x

[18] Westert, G. P., Nieboer, A. P., \& Groenewegen, P. P. Variation in duration of hospital stay between hospitals and between doctors within hospitals. Soc Sci.Med. 1993; 37: 833-839. http://dx.doi.org/10.1016/0277-9536(93)90377-G

[19] Weingarten S, Riedinger MS, Sandhu M, Bowers C, Ellrodt AG, Nunn C, Hobson P, Greengold N. Can practice guidelines safely reduce hospital length of stay? Results from a multicenter interventional study. Am J Med. 1998 Jul; 105(1): 33-40. http://dx.doi.org/10.1016/S0002-9343(98)00129-6 